\title{
Comparação dos testes sorológicos de Imunofluorescência Indireta, Conglutinação Rápida, ELISA indireto e ELISA por competição para a detecção de anticorpos contra o Anaplasma marginale em soros de bovinos de diferentes áreas enzoóticas ${ }^{1}$
}

\section{Comparison of the serologic tests of Indirect Immunofluorescence, Rapid Conglutination, Indirect ELISA and Competition ELISA for detection of antibodies against Anaplasma marginale in cattle sera from different enzootic areas}

\author{
Elizabete Regina Marangoni Marana ${ }^{2}$; Amauri A. Alfieri ${ }^{3}$; Gisele Maria de Andrade ${ }^{4}$; \\ Roberta Lemos Freire ${ }^{3}$ J João Luís Garcia ${ }^{3}$; Odilon Vidotto ${ }^{3 *}$
}

\section{Resumo}

\begin{abstract}
Os testes sorológicos de Conglutinação Rápida (TCR) Imunofluorescência Indireta (IFI) e Imunoenzimáticos Indireto (iELISA) utilizando ELISA por competição (cELISA), como padrão ouro, foram avaliados comparativamente para a detecção de anticorpos contra o Anaplasma marginale. Foram utilizadas 453 amostras de soros sangüíneos de bovinos vacinados e não-vacinados e de áreas de estabilidade e instabilidade enzoótica. O iELISA, IFI e TCR apresentaram respectivamente, índice kappa $=0,77$ (substancial), 0,57 e 0,49 (moderado), sensibilidade de $90,6 \%, 90,2 \%$ e $73,7 \%$ e especificidade de $86,6 \%, 62,8 \%$, e 79,3\%. O iELISA apresentou o melhor desempenho e maior especificidade, podendo ser indicado na avaliação do perfil sorológico de rebanhos, na detecção de animais persistentemente infectados e de animais submetidos a programas de vacinação. As técnicas de IFI e TCR, mesmo apresentando desempenho inferior, podem ser recomendadas para a realização de inquéritos epidemiológicos e para o monitoramento de animais em trânsito entre as diferentes regiões geográficas. Palavras-chave: Bovinos, Anaplasma marginale, TCR, IFI, iELISA, cELISA
\end{abstract}

\footnotetext{
1 Parte da Dissertação de Mestrado da primeira autora apresentada ao Programa de Pós-graduação em Ciência Animal, Centro de Ciências Agrárias, Universidade Estadual de Londrina (UEL).

2 Médico Veterinário, Doutor, Técnico de Nível Superior, Laboratório de Protozoologia, Departamento de Medicina Veterinária Preventiva (DMVP), UEL, Londrina, PR.

3 Professor, Doutor, DMVP, UEL. Rodovia Celso Garcia Cid, PR 445, Km 380; Campus Universitário; Caixa Postal 6001. CEP: 86051-990, Londrina, PR. Fone/Fax: 43 33714485. E-mail: vidotto@uel.br

4 Médico Veterinário, Doutor, Técnico de Nível Superior, UNESP-Jaboticabal, SP.

* Autor para correspondência
} 


\begin{abstract}
The serological techniques Rapid Conglutination Test (RCT), Indirect ELISA (iELISA) and Indirect Immunofluorescent Assay (IFA), using the competition ELISA (cELISA) as gold test, were comparatively evaluated to detect antibodies against Anaplasma marginale. A total of 453 sera from vaccinated and non vaccinated cattle and, collected from enzootic stability and instability areas were tested. iELISA, IFA and TCR presented kappa index $=0.77$ (substantial); 0.57 and 0.49 (moderate), sensibility of 90.6\%; $90.2 \%$ and $73.7 \%$ and specificity of $86.6 \% ; 62.8 \%$, and $79.3 \%$, respectively. Therefore, iELISA presented better specificity than IFA and RCT, and can be indicated for more detailed serological investigations, detection of persistently infected animals in cattle herds and for monitorating of vaccination programs. IFA and TCR can be used in prevalence studies and to monitor cattle movement between different geographical regions.
\end{abstract}

Key words: Cattle, Anaplasma marginale, TCR, IFA, iELISA, cELISA

\section{Introdução}

O Anaplasma marginale ocorre em regiões tropicais, subtropicais e temperadas, ocasionando perdas econômicas consideráveis à bovinocultura mundial (PALMER, 1989). A infecção pode ocasionar redução na produção de leite e carne, perda de peso, abortamentos e mortes de animais com infecção clínica (PALMER; McGUIRE, 1984). O Brasil apresenta áreas de estabilidade enzoótica, com alta prevalência de $A$. marginale (MADRUGA et al., 1994; ARTILES et al., 1995; VIDOTTO et al., 1997; ARAÚJO et al., 1997) e áreas de instabilidade enzoótica (OLIVEIRA et al., 1992), onde a maioria dos animais não é infectada. Essa diversidade implica na exigência do conhecimento do perfil imunológico dos rebanhos bovinos em distintas regiões geográficas brasileiras.

Várias técnicas sorológicas, com graus variados de sensibilidade e especificidade, foram desenvolvidas para a detecção anticorpos para o A. marginale. Entre as técnicas mais utilizadas se destacam o teste da conglutinação rápida (TCR) (MADRUGA et al., 1987), a aglutinação pelo látex (RODGERS et al., 1997), a hemaglutinação (CARSON \& BUENING, 1979), a fixação de complemento (FC) (BÖSE et al., 1995) e a imunofluorescência indireta (IFI) (MADRUGA et al., 1986).

$\mathrm{O}$ método ELISA indireto para a detecção de anticorpos contra o $A$. marginale tem apresentado sensibilidade e especificidade inadequadas quando se busca a realização um diagnóstico mais acurado (DUZGUN et al., 1988; MONTENEGRO-JAMES et al., 1990). A padronização de um sistema de ELISA por competição (cELISA), utilizando a proteína majoritária de superfície 5 recombinante (MSP5r) de $19 \mathrm{kDa}$ do A. marginale, presente em cepas de regiões geográficas distintas, como antígeno associado ao anticorpo monoclonal específico proporcionou incremento substancial nos resultados da técnica (KNOWLES et al., 1996).

O objetivo deste trabalho foi comparar os testes de TCR, IFI e iELISA na detecção de anticorpos contra A. marginale, tendo como prova ouro o cELISA, em soros de animais importados vacinados e não vacinados e em soros de animais de áreas geográficas brasileiras com estabilidade e instabilidade enzoótica.

\section{Material e métodos}

Amostras de soro e antígenos de A. marginale

Os 453 soros utilizados no experimento são de animais importados não vacinados e vacinados contra A. marginale e soros de bovinos oriundos do Brasil provenientes de áreas de instabilidade e de estabilidade enzoótica para anaplasmose. A Tabela 1 apresenta a distribuição dos soros de acordo com a procedência. 
Os soros utilizados como controles negativos nas quatro provas avaliadas foram obtidos de dois bezerros livres do $A$. marginale e monitorados pela técnica da reação em cadeia da polimerase (PCR) (VIDOTTO et al. 1995b), mantidos em condições de isolamento. Um terceiro soro de bovino nãoreagente para o $A$. marginale, obtido de animal também mantido em isolamento, foi fornecido pela
EMBRAPA CNPGC - Campo Grande, MS. Como controles positivos foram utilizados quatro soros obtidos de bovinos inoculados experimentalmente com o A. marginale.

Os antígenos utilizados nos diferentes testes sorológicos foram fornecidos pelo Laboratório de Imunoparasitologia da EMBRAPA/CNPGC, Campo Grande-MS.

Tabela 1. Amostras de soros de bovinos utilizadas na comparação das técnicas de IFI, TCR, ELISA e cELISA para a detecção de anticorpos anti-Anaplasma marginale.

\begin{tabular}{cccc}
\hline $\begin{array}{c}\text { Procedência } \\
\text { dos bovinos }\end{array}$ & Estatus imunológico & Faixa Etária meses & Amostras de soros \\
\hline Itália & Não vacinado & 12 a 60 & 33 \\
Canadá & Não vacinado & 14 a 28 & 30 \\
Itália & Após vacinação & 15 a 63 & 33 \\
Canadá & Após vacinação & 17 a 31 & 30 \\
Argentina & Vacinado & 12 a 24 & 100 \\
Bagé - RS & Instab. enzoótica & 12 a 24 & 104 \\
Londrina- PR & Estab. enzoótica & 12 a 48 & 123 \\
\hline Total & & 453 \\
\hline
\end{tabular}

\section{Teste de Imunofluorescência Indireta (IFI)}

A IFI foi realizada de acordo com o procedimento descrito por MADRUGA et al. (1986b). Foram utilizados $10 \mathrm{ml}$ dos soros controle negativos e positivos diluídos 1:320 e os soros a serem testados diluídos 1:320 e 1:640. Utilizou-se como conjugado a anti-IgG bovina total marcada com isotiocianato de fluoresceína (FITC), produzida em coelho $\left(\right.$ SIGMA $\left.^{\circledR}\right)$, na diluição de 1:800 em PBS, pH 7,2. A leitura foi realizada em microscópio Nikon Labophot - Episcopic Fluorescence Attachment "EF"/"EFA" (Nippon Kogaku K.K.) a 450hm, com aumento de 400x.

\section{Teste de Conglutinação Rápida (TCR)}

O TCR foi realizado segundo Madruga et al. (1995). Foram adicionados $15 \mathrm{ml}$ do soro bovino, 30 $\mathrm{ml}$ de fator sérico bovino e $15 \mathrm{ml}$ do antígeno em placa de vidro, homogeneizados e agitados por $8 \mathrm{~min}$. O critério de interpretação foi negativo (-) sem a formação de grumos; positivo fraco $(+)$ com pouca formação de grumos; positivo $(++)$, presença regular de grumos e positivo forte $(+++)$ com intensa formação de grumos.

\section{Teste de ELISA Indireto (iELISA)}

O iELISA foi realizado segundo Madruga et al. (2000). O ajuste da densidade óptica (DO) para a determinação do ponto discriminativo foi calculado pela equação $\mathrm{F}=\mathrm{PO}-\mathrm{NO} / \mathrm{PT}-\mathrm{NT}$. Onde $\mathrm{F}$ é o fator de ajuste, NO a média das DO dos soros negativos, PO a média das DO dos soros positivos, PT e NT as médias dos controles positivo e negativo de cada placa teste, respectivamente. $\mathrm{O}$ ajuste da DO dos soros testes foi obtido pela equação $\mathrm{ADO}=\mathrm{F}(\mathrm{ST}-\mathrm{NT})+\mathrm{NO}$, onde ST é a média da DO do soro testado em triplicata. O ponto discriminativo foi obtido pela média da DO dos soros negativos acrescida de dois desvios padrão. 
Teste de ELISA por Competição(cELISA)

O cELISA foi realizado segundo Knowles et al. (1996). A leitura foi efetuada em leitor de ELISA automatizado Bio-Tek Instruments ${ }^{\circledR}$, INC Modelo ELx 800) a 405 çm e um valor de três desvios padrão abaixo da média da DO dos soros negativos, representando $25 \%$ de inibição, foi usado como ponto de corte para a identificação dos soros negativos.

\section{Análise estatística}

Para a comparação dos resultados obtidos nas quatro técnicas TCR, IFI, iELISA e cELISA avaliadas utilizou-se o teste de concordância por meio da determinação do coeficiente de kappa e de concordância percentual com cálculos realizados pelo programa Epi Info 6.04 (DEAN et al., 1994; KRAMER; FEINSTEIN, 1981).

\section{Resultados e discussão}

A reatividade das amostras de soros nas quatro técnicas avaliadas em conjunto e de acordo com as quatro situações de cada grupo de animais pode ser visualizada na Tabela 2.

A IFI apresentou a maior percentagem de resultados positivos $(69,3 \%)$, seguida do iELISA
(58,7\%), cELISA $(57,2 \%)$ e do TCR $(56,3 \%)$. O cELISA foi utilizado como padrão ouro para a obtenção do índice de concordância kappa, as taxas de sensibilidade e especificidade e os valores preditivos positivos e negativos na análise comparativa entre os quatro métodos sorológicos avaliados (Tabela 2). Torioni et al. (1999) avaliaram o teste confrontando com resultados obtidos com "nested PCR", hibridização e análise de seqüenciamento do gene que codifica a MSP5 de $A$. marginale, em soros de bovinos inoculados e portadores sãos, e encontraram especificidade de $96 \%$ e especificidade de $95 \%$.

Gonzalez et al. (1978) comparando a IFI e o TCR no diagnóstico da anaplasmose observaram que a IFI detectou $97 \%$ de animais positivos e o TCR 79\%. No presente trabalho, a IFI detectou $69,3 \%$ e o TCR $56,3 \%$ de soros positivos. Vidotto et al. (1995 e 1997) analisaram soros bovinos provenientes da região de Londrina, PR pelos testes de IFI e cELISA e obtiveram diferença de $19,5 \%$, enquanto que no presente trabalho a IFI detectou 314 soros reagentes para A. marginale enquanto o cELISA detectou 259 soros reagentes, num total de 55 soros, correspondendo a $11,3 \%$ de soros positivos (55/453) a mais que aqueles detectados pelo cELISA (Tabela 2). Este resultado sugere maior sensibilidade e menor especificidade da IFI frente ao cELISA.

Tabela 2. Freqüência dos resultados positivos e negativos obtidos para anticorpos contra o Anaplasma marginale, em soros de 453 bovinos distribuídos de acordo com as técnicas utilizadas.

\begin{tabular}{lccccccc}
\hline \multicolumn{1}{c}{ Testes } & \multicolumn{1}{c}{ Resultado (\%) } & \multicolumn{1}{c}{ Sensibili- } & Especifici- \\
dade & Positivo & Negativo & $\begin{array}{c}\text { Valor } \\
\text { Preditivo } \\
\text { Positivo }\end{array}$ & $\begin{array}{c}\text { Valor } \\
\text { Preditivo } \\
\text { Negativo }\end{array}$ & $k$ \\
\hline TCR & $255(56,3)$ & $198(43,7)$ & $73,7 \%$ & $79,3 \%$ & $89,5 \%$ & $57,5 \%$ & $0,49(\mathrm{M})$ \\
IFI & $314(69,3)$ & $139(28,7)$ & $90,2 \%$ & $62,8 \%$ & $77,7 \%$ & $84,9 \%$ & $0,57(\mathrm{M})$ \\
iELISA & $266(58,3)$ & $191(42,2)$ & $90,6 \%$ & $86,6 \%$ & $90,6 \%$ & $86,6 \%$ & $0,77(\mathrm{~S})$ \\
cELISA & $259(57,3)$ & $194(42,8)$ & & & & & \\
\hline
\end{tabular}

$k$ - coeficiente de kappa $(<0,0$ a 1,0$) ; \mathrm{P}=$ pobre: $<0.0 ; \mathrm{F}=$ fraco: $0,0-0.20 ; \mathrm{R}=$ razoável: $0.21-0.40 ; \mathrm{M}=$ moderado: 0.41 $0.60 ; \mathrm{S}=$ substancial: $0.61-0.80 ; \mathrm{QP}=$ quase perfeito: $0.81-1.00$. 
Molloy et al. (1998), ao compararem o teste de cELISA com o teste do Cartão, analisando 757 soros de bovinos oriundos de área endêmica na Austrália, observaram $k=0,73$ (Substancial) com uma concordância percentual de $91,5 \%$. No presente trabalho o TCR apresentou $k=0,49(\mathrm{M})$, com $77 \%$ de concordância percentual tendo o cELISA como teste ouro, resultados que diferem significativamente daqueles obtidos pelos pesquisadores australianos.

Araújo et al. (1997), em estudo comparativo entre os testes ELISA, TCR e IFI para a detecção de anticorpos para o $A$. marginale, analisaram soros de três regiões do estado da Bahia e encontraram alta prevalência. Constataram concordância de resultados de 89,2\% entre ELISA e TCR, 90\% entre ELISA e IFI e $88,9 \%$ entre IFI e TCR, onde os três testes sorológicos apresentaram bom desempenho na detecção de anticorpos contra o $A$. marginale. No presente trabalho, os testes apresentaram: $75 \%$ de concordância entre iELISA e TCR, 76,6\% entre ELISA e IFI e 75,9\% entre IFI e TCR. Estes resultados diferem em aproximadamente 15 pontos percentuais daqueles obtidos por Araújo et al. (1997).

Madruga et al. (2000), ao avaliarem o desempenho do ELISA frente à IFI relataram 100\% de sensibilidade e $97 \%$ de especificidade. Os valores obtidos no presente trabalho, avaliando o desempenho do ELISA e IFI, foram $90,6 \%$ e $90,2 \%$, de sensibilidade e $86,6 \%$ e $62,8 \%$ de especificidade respectivamente, não foram percentuais tão elevados, possivelmente por terem sido utilizados soros de grupos de animais provenientes de regiões distintas com perfis imunológicos bastante diversificados.

As médias percentuais dos soros positivos obtidas sugerem uma distribuição homogênea para as quatro técnicas avaliadas, porém os resultados individuais de cada soro frente as diferentes técnicas apresentaram discrepância. Os resultados coincidentes nas 453 amostras de soros analisadas alcançaram $61,8 \%(n=280)$, dos quais $68,6 \%(n=192)$ foram soros reagentes e $31,4 \%(n=88)$ de soros nãoreagentes. Dessa forma $38 \%(n=172)$ dos resultados se mostraram discordantes em pelo menos um dos testes com uma variedade de combinações sugerindo prováveis resultados falso-positivo ou falso-negativo.

Os testes iELISA e cELISA apresentaram menor percentual $(6,6 \%)$ de resultados discordantes $(n=30)$, podendo-se considerar soros com resultados negativos $(35,8 \%$ das amostras testadas) aos dois sistemas imunoenzimáticos como prováveis negativos verdadeiros $(n=162)$, uma vez que estes testes apresentaram a maior especificidade e sensibilidade.

Os soros foram analisados segundo o estatus imunológico utilizando os quatro testes sorológicos (Tabela 3), observando-se que animais após vacinação e de áreas de estabilidade enzoótica apresentaram valores percentuais maiores e semelhantes, quando comparados aos soros de animais não vacinados e oriundos de área de instabilidade enzoótica. Essas variações sugerem que, quando se analisou rebanhos com maior freqüência de animais soropositivos, os quatro testes apresentaram resultados semelhantes, enquanto em rebanhos com menor freqüência de soropositivos, os testes mostraram resultados discrepantes.

A Tabela 4 apresenta os resultados obtidos nos quatro sistemas de diagnóstico sorológico analisados dois a dois pelo teste de concordância. O coeficiente kappa $(k)$ apresentou melhor concordância (substancial) entre o iELISA e o cELISA, com $k=$ 0,77 . O índice $k$ para IFI e TCR apresentou concordância moderada, variando entre 0,58 e 0,49, respectivamente, ao serem analisados frente ao cELISA. Estes últimos dois testes devem ser utilizados com maior cautela ao se considerar circunstâncias específicas de cada rebanho e sua situação epidemiológica.

Nas áreas de instabilidade enzoótica é importante o conhecimento do estatus imunológico dos animais do rebanho, considerando-se a necessidade de um manejo adequado, controle de vetores, vacinação e os riscos na importação e exportação de animais. O iELISA é um teste bastante sensível para detectar esses animais, sendo o cELISA um teste mais específico, capaz de identificar com maior precisão os animais negativos, fator importante nas importações de animais. 
Tabela 3. Reatividade das amostras de soros de bovinos utilizadas na comparação das técnicas de IFI, TCR, ELISA e cELISA para a detecção de anticorpos para o Anaplasma marginale.

\begin{tabular}{|c|c|c|c|c|c|c|}
\hline \multirow{2}{*}{$\begin{array}{c}\text { Estatus } \\
\text { imunológico }\end{array}$} & \multirow[t]{2}{*}{ Soros Bovinos } & TCR & \multicolumn{2}{|c|}{ IFI } & iELISA & cELISA \\
\hline & & Pos $(\%)$ & Pos & $(\%)$ & Pos. $\%$ & Pos. $\%$ \\
\hline Não vacinado & 63 & $4(6,3)$ & 12 & $(19,0)$ & $20 \quad(31,7)$ & $13(20,6)$ \\
\hline Após vacinação & 63 & $55(87,3)$ & 60 & $(95,2)$ & $59 \quad(93,6)$ & $57 \quad(90,5)$ \\
\hline Vacinado & 100 & $56(56,0)$ & 76 & $(76,0)$ & $61(61,00)$ & $66(66,0)$ \\
\hline $\begin{array}{l}\text { Instab. } \\
\text { enzoótica }\end{array}$ & 104 & $29 \quad(27,9)$ & 36 & $(34,6)$ & $14(13,5)$ & $12(11,5)$ \\
\hline $\begin{array}{l}\text { Estab. } \\
\text { enzoótica }\end{array}$ & 123 & $111(90,2)$ & 120 & $(97,6)$ & $113(91,9)$ & $117(95,1)$ \\
\hline TOTAL & $453(100)$ & $255(56,3)$ & 314 & $(69,3)$ & $266(58,7)$ & $265(58,5)$ \\
\hline
\end{tabular}

Tabela 4. Distribuição dos resultados da análise de concordância, na contingência 2x2, entre os testes de TCR, IFI, ELISA e cELISA.

\begin{tabular}{lcccc}
\hline & TRC & IFI & iELISA & \multicolumn{2}{c}{ cELISA } \\
& $k$ & $k$ & $k$ & $k$ \\
\hline TCR & 1,00 & $0,52^{\mathrm{M}}$ & $0,49^{\mathrm{M}}$ & $0,49^{\mathrm{M}}$ \\
IFI & - & 1,00 & $0,50^{\mathrm{M}}$ & $0,58^{\mathrm{M}}$ \\
iELISA & - & - & 1,00 & $0,77^{\mathrm{s}}$ \\
cELISA & - & - & - & 1,00 \\
\hline
\end{tabular}

$k$ - coeficiente de kappa $(<0,0$ a 1,0$) ; \mathrm{P}=$ pobre $:<0,0 ; \mathrm{F}=$ fraco: $0,0-0,20 ; \mathrm{R}=$ razoável: $0,21-0,40 ; \mathrm{M}=$ moderado: 0,41 0,$60 ; \mathrm{S}=$ substancial: $0,61-0,80 ; \mathrm{QP}=$ quase perfeito: $0,81-1,00$

A Tabela 5 mostra os índices Kappa, sensibilidade e especificidade dos soros de animais importados nãoimunizados e pós-vacinação submetidos aos testes de TCR, IFI e iELISA, frente ao cELISA como teste ouro. Neste contexto, o melhor $k(0,86)$ foi do iELISA, sugerindo que os resultados apresentados por este teste são semelhantes aos do cELISA, com boa sensibilidade, porém com menor especificidade. Os testes TCR e IFI apresentaram um $k$ moderado, evidenciando inferioridade destes testes em relação ao iELISA e cELISA. Na prática, os testes imunoenzimáticos apresentaram melhor desempenho quando foram analisados animais provenientes de regiões livres de anaplasmose e que foram posteriormente vacinados. Enquanto que a IFI, com sensibilidade maior que o TCR, detectaria mais animais positivos e este último, com maior especificidade, identificaria os animais verdadeiramente positivos.

Analisando soros de animais provenientes de regiões de instabilidade e estabilidade enzoótica foram obtidos melhores resultados de $k$ e especificidade para o iELISA, comparados àqueles alcançados pelo TCR e pela IFI, permitindo identificar com maior precisão os animais verdadeiramente positivos (Tabela 6). 
Tabela 5. Resultados da comparação dos testes TCR, IFI e iELISA com soros de animais importados e depois vacinados contra A. marginale com o cELISA como teste ouro.

\begin{tabular}{cccccc}
\hline Teste & $\begin{array}{c}\text { Kappa } \\
(k)\end{array}$ & $\begin{array}{c}\text { Sensibilidade } \\
(\%)\end{array}$ & $\begin{array}{c}\text { Especificidade } \\
(\%)\end{array}$ & $\begin{array}{c}\text { Valor Preditivo } \\
\text { positivo }(\%)\end{array}$ & $\begin{array}{c}\text { Valor Preditivo } \\
\text { Negativo }(\%)\end{array}$ \\
\hline TCR & $0,52^{\mathrm{M}}$ & 71,4 & 83,9 & 84,7 & 70,1 \\
IFI & $0,54^{\mathrm{M}}$ & 80,0 & 71,4 & 77,8 & 74,1 \\
iELISA & $0,86^{\text {QP }}$ & 94,3 & 76,4 & 83,5 & 91,5 \\
\hline
\end{tabular}

$k$ - coeficiente de kappa $(<0,0$ a 1,0$) ; \mathrm{P}=$ pobre: $<0,0 ; \mathrm{F}=$ fraco: $0,0-0,20 ; \mathrm{R}=$ razoável: $0,21-0,40 ; \mathrm{M}=$ moderado: 0,41 0,$60 ; \mathrm{S}=$ substancial: $0,61-0,80 ; \mathrm{QP}=$ quase perfeito: $0,81-1,00$

Tabela 6. Resultados da comparação dos testes TCR, IFI e iELISA com soros de animais oriundos de áreas de instabilidade e estabilidade enzoótica para anaplasmose bovina contra $A$. marginale com o cELISA como teste ouro.

\begin{tabular}{cccccc}
\hline Teste & $\begin{array}{c}\text { Kappa } \\
(k)\end{array}$ & $\begin{array}{c}\text { Sensibilidade } \\
(\%)\end{array}$ & $\begin{array}{c}\text { Especificidade } \\
(\%)\end{array}$ & $\begin{array}{c}\text { Valor Preditivo } \\
\text { positivo (\%) }\end{array}$ & $\begin{array}{c}\text { Valor Preditivo } \\
\text { Negativo (\%) }\end{array}$ \\
\hline TCR & $0,65^{\mathrm{M}}$ & 89,1 & 74,5 & 82,1 & 83,9 \\
IFI & $0,66^{\mathrm{M}}$ & 96,1 & 67,3 & 79,5 & 93,0 \\
iELISA & $0,77^{\mathrm{S}}$ & 89,1 & 87,8 & 90,6 & 86,0 \\
\hline
\end{tabular}

$k$ - coeficiente de kappa $(<0,0$ a 1,0); $\mathrm{P}=$ pobre: $<0,0 ; \mathrm{F}=$ fraco: $0,0-0,20 ; \mathrm{R}=$ razoável: $0,21-0,40 ; \mathrm{M}=$ moderado: 0,41 0,$60 ; \mathrm{S}=$ substancial: $0,61-0,80 ; \mathrm{QP}=$ quase perfeito: $0,81-1,00$

Concluindo, a IFI e o TCR apresentaram coeficientes de concordância próximos. O TCR apresentou resultados que indicam sua utilização em levantamentos epidemiológicos, por apresentar-se como um teste simples e rápido que não necessita de equipamentos sofisticados. A IFI, com alta sensibilidade, apresentou resultados que sustentam seu uso em inquéritos epidemiológicos, na titulação dos soros e no acompanhamento das variações sorológicas apresentadas pelos rebanhos. Os testes do iELISA e cELISA são mais adequados aos estudos epidemiológicos mais elaborados e de maior confiabilidade em áreas de instabilidade enzoótica, onde a prevalência é variável. O iELISA, por sua alta sensibilidade, pode ser empregado nas situações de importações e de trânsito interno de animais oriundos de áreas com alta prevalência que poderiam atuar como fontes de infecção nas áreas onde a anaplasmose não está presente. O cELISA tem se apresentado como técnica de alta especificidade, que possibilita estimar o perfil sorológico dos animais, detectar animais portadores do A. marginale e avaliar o estatus imunológico de animais submetidos a programas de vacinação.

\section{Agradecimentos}

À Coordenação de Aperfeiçoamento de Pessoal de Nível Superior - CAPES, pelo apoio financeiro. À Empresa Brasileira de Pesquisa Agropecuária Centro Nacional de Pesquisa de Gado de Corte, EMBRAPA CNPGC, Campo Grande, MS e ao Dr. Cláudio Roberto Madruga pelos antígenos e amostras sorológicas. 


\section{Referências}

ARAÚJO, F. R.; LEAL, C. R. B.; BASTOS, P. A. S.; MADRUGA, C. R.; MARQUES, A. P. C. Comparação dos testes de Imunoadsorção Enzimática, Conglutinação Rápida e Imunofluorescência Indireta na detecção de anticorpos contra Anaplasma marginale. Revista Brasileira de Parasitologia Veterinária, v.6, n.2, supl.1, p.323, 1997.

ARTILES, J.; ALVES-BRANCO, F. de P. J.; MARTINS, J. R.; CORREA, L. B.; SAPPER, M. F. de M. Prevalência de Babesia bovis, Babesia bigemina e Anaplasma marginale no município de Bagé, RS. Revista Brasileira de Parasitologia Veterinária, v.6, n.2, supl.1, p.179, 1995.

BÖSE, R.; JORGENSEN, W. K.; DALGLIESH, R. J.; FRIEDHOFF, K. T.; de VOS, A. J. Current and future trends in the diagnosis of babesiosis. Veterinary Parasitology. n.57, p. 61-74, 1995.

CARSON, C. A.; BUENING, G. M. The immune response of cattle to live and inactivated Anaplasma vacines and response challenge. South African Veterinary Association, v.38, n.4, p. 330-331, 1979 .

DEAN, G. A. , DEAN, A. J.; COULOMBIER, D., BRENDEL, K. A., SMITH, D. C.; BURTON, A. H.; DICKER, R. C.; SULIVAN, K. M.; FAGAN, R. F., ARNER, T. G. Epi Info, Version 6: a word processing, database and statistic program for epidemiology on microcomputers. Atlanta, Center for Diseases Control and Prevention, 1994.

DUZGUN, A.; SCHUNTNER, C. A.; WRIGHT, I. G.; LEATCH, G.; WALTISBULHL. A sensitive ELISA technique for the diagnosis of Anaplasma marginale infections. Veterinary Parasitology, v.29, p.1-7, 1988.

GONZALEZ, E. F.; LONG, R. F.; TODOROVIC, R. A. Comparison of the Complement-Fixation, Indirect Fluorescent Antibody, and Card Agglutination Tests for the Diagnosis of Bovine Anaplasmosis. American Journal of Veterinary Research, v.39, n.9, p.1538-1531, Sep. 1978.

KNOWLES, D. P.; TORIONI de ECHAIDE, S.; PALMER, G. McGUIRE, T.; STILLER, D.; McELWAIN, T. Antibody against an Anaplasma marginale MSP5 epitope common to tick and erythrocyte stages identifies persistently infected cattle. Journal of Clinical Microbiology, v. 34, n.9, p.2225-2230, 1996.

KRAMER, M. S.; FEINSTEIN, A. R. Clinical biostatistics LIV. The biostatistcs of concordance. Clinical Pharmacology and Therapeutics, v.29, n.1, p.111-123, 1981.

MADRUGA, C. R.; KESSLER, R. H.; SACCO, A. M. S.; JESUS, E. F. de; MIGUITA, C. T. Produção de antígenos e análise preliminar do teste de Imunofluorescência Indireta para diagnóstico de anticorpos contra Anaplasma marginale, Centro Nacional de Pesquisa de Gado de Corte (EMBRAPA-CNPGC). n.31, p.1-4, Out, 1986.

MADRUGA, C. R.; BERNE, M. E. A.; KESSLER, R. H.; GOMES, R. F. C.; LIMA, J. G.; SCHENK, M. A. M. Diagnóstico da Tristeza Parasitária bovina no Estado de Mato Grosso do Sul: Inquérito de opinião. Fundação Cargill. (EMBRAPA-CNPGC.).n.38, 7 p., 1987.

MADRUGA, C. R.; HONER, M. R.; ANDREOTTI, R.; ARAÚJO, F. R.; SANTARÉM, V. Prevalência de Anaplasma marginale em três regiões do estado da Paraíba. In: CONGRESSO INTERNACIONAL DE MEDICINA VETERINÁRIA EMLÍNGUA PORTUGUESA, 6, 1994. Salvador, BA. Anais... Bahia, 1994, p. 350-352.

MADRUGA, C. R.; KESSLER, R. H.; SCHENK, M. A. M.; HONER, M. R.; MIGUITA, M. Análise de testes de conglutinação rápida para detecção de anticorpos contra Babesia bovis e Babesia bigemina. Arquivo Brasileiro de Medicina Veterinária e Zootecnia, Belo Horizonte, v.47, n.5, p. 649-657, 1995.

MADRUGA, C. R.; MARQUES, A. P. C.; LEAL, C. R. B.; CARVALHO, C. M. E. ARAÚJO, F. R.; KESSLER, R. H. Evaluation of an enzyme linked immunosorbent assay to detect antibodies against Anaplasma marginale. Pesquisa Veterinária Brasileira, Rio de Janeiro, v.20, n.3, p.109$112,2000$.

MOLLOY, J. B.; BOWLES, P. M.; KNOWLES, D. P.; McELWAIN, T.F.; BOCK, R.E.; KINGSTON, T.G.; BLIGHT, G.W.; DALGLIESH, R.J. Comparison of a competitive inhibition ELISA and the card agglutination test for detection of antibodies to Anaplasma marginale and Anaplasma centrale in cattle. Australian Veterinary Journal, v.77, n.4, p.245-249, 1999.

MONTENEGRO-JAMES, S.; GUILLE, A. T.; TAPANG, P.; ABBEL-GAWAD, A.; TORO, M.; RISTIC, M. Use of the dot enzyme-linked immunosorbent assay with isolated Anaplasma marginale initial bodies for serodiagnosis of anaplasmosis in cattle. American Journal of Veterinary Research, v.51, n.10, p.1518-1521, 1990.

OLIVEIRA, A. A. de; PEDREIRA, P. A. S.; ALMEIDA, M. P. R. S de; De OLIVEIRA, A. A.; De ALMEIDA, M. P. R. S. Doenças de bezerros. II. Epidemiologia da anaplasmose no estado de Sergipe. Arquivo Brasileiro de Medicina Veterinária e Zootecnia, Belo Horizonte, v. 44, n. 5, p. 377-386, 1992.

PALMER, G. H.; McGUIRE, T. C. Immune serum against Anaplasma marginale initial bodies neutralizes infectivity for cattle. Journal of Immunology, v.133, n.2, p.1010-1015, 1984. 
PALMER, G. H. Anaplasma Vacines. In: WRIGHT, I. G. Veterinary Protozoan and Haemopasite Vaccines. Roca Raton, Florida. c.1, p.1-29, 1989.

RODGERS, S. J.; SALIKI, J. T.; BLOUIN, E. F.; KOCAN, K. M. The development of a semi-automated latex agglunatination test for the dectetion of antibodies to Anaplasma marginale using a cell culture-derived antigen. In: BIENNAL MEETING SOCIETY FOR TROPICAL VETERINARY MEDICINE, 4, 1997, Montepellier, França. Anais... França 1997, p.63. Resumo.

ROSE, F. E.; AMERAULT, T. E.; ROBY, T. O. Roles of conglutinin, complement, and antibody size in the card agglutination test for bovine anaplasmosis. American Journal of Veterinary Research, v.35, n.9, p. 1147-1151, 1974.

ROSE, J. E.; AMERAULT, T. E.; ROBY, T. O.; MARTIN, W. H. Serum levels of conglutinin, complement, and immunoconglutinin in cattle infected with Anaplasma marginale. American Journal of Veterinary Reseach, v.39, n.5, p. 791-793, 1978.

SACKET, D. L.; HAYNES, R. B.; GUYATT, G. H.; TWUGWELL, P. Clinical Epidemiology: a basic science for clinical medicine. Little, Brown and Company, Second Edition, Boston, 441p. 1991.
TORIONIDEECHAIDE, S., KNOWLES, D. P., McGUIRRE, T. F., PALMER, G. H., SUAREZ, C. E., McELWAIN, T. F. Detection of cattle naturally infected with Anaplasma marginale in a region of endemicity by nested PCR and a competitive enzyme-linked immunosorbent assay using recombinant major surface protein 5. Journal of Clinical Microbiology. v. 36, n. 3, p. 777-782, 1998.

VIDOTTO, O; YAMAMURA, M. H.; ANDRADE, G. M.; BARBOSA, C. da S.; FREIRE, R. L.; VIDOTTO, M. C. Ocorrência da Babesia bigemina, B. bovis e Anaplasma marginale em rebanhos de bovinos leiteiros da região de Londrina, PR Revista Brasileira de Parasitologia Veterinária, v.4, n. 2, supl.2, p. 184, 1995.

VIDOTTO, M. C; YAMAMURA, M. H.; KWOLES, D. P.; PALMER, G. H.; ANDRADE, G. M.; VIDOTTO, O. Deteç̧ão de Anaplasma marginale em Boophilus microplus pela técnica do PCR. Revista Brasileira de Parasitologia Veterinária, v.4, n.2, supl. 2, p.186, 1995 b.

VIDOTTO, M. C.; VIDOTTO, O.; ANDRADE, G. M.; PALMER, G. H.; McELWAIN, T. KWOLES, D. C. Seroprevalence of Anaplasma marginale on cattle in Parana State, Brasil, by MSP5 competitive inhibition ELISA. Annals of New York Academy of Sciences, v. 849, p. 424-426, 1998. 